UDC: 811.111 '255.4:378.124 https://doi.org/10.22190/JTESAP1803377D

\title{
EVOLVING LEARNING PARADIGMS: AFFORDANCES AND CONSTRAINTS
}

\author{
Ljiljana Vukićević-Đorđević \\ Faculty of Science, University of Kragujevac \\ E-Mail: ljvukicevic@yahoo.co.uk
}

\begin{abstract}
A successful teacher is not only a person with specialist knowledge and prominent personal features, but the one with skills and capacities emphasizing particularly his/her managerial qualities. In addition, English for Specific Purposes (ESP) teachers face a specificity dealing with two subject-matter fields - the English language and specific subject-matter knowledge, be it science, humanities, engineering, or anything else. Are general pedagogical practices overemphasized and often at the expense of content knowledge? In our opinion, teachers' knowledge of student thinking and learning is more related to their emotional intelligence and psychology than pedagogy. Instead of memorizing facts, students are to be taught to search for information, to connect things, and enable the development of integrative knowledge in a multidisciplinary education. In such a learning environment, the responsibility of teachers is not only in their teaching but in facilitating learning by doing. Teachers' ability to use English in a way that encourages learning in their students, where accuracy, fluency, and intelligibility are implied as necessary, is in our opinion above all theories, especially in times when motivation in students is constantly decreasing and dazzling lights 'are killing softly' our society of gadgets and gizmos.
\end{abstract}

Key words: subject-matter content, concept-based teaching, skill, knowledge, performance

\section{INTRODUCTION}

Bearing in mind that teaching is a cognitive activity which is highly complex and which integrates various domains of knowledge, ESP teachers are often seen as the ones who beside the mastery of an occupational field and academic English, adopt generic knowledge comprising teaching/learning pedagogy, theories about learning, approaches and methods of teaching, methods of assessment, etc. Whatever they do, both teachers and students connect with their prior experiences, and thus having engaged in active learning, teachers facilitate understanding of knowledge and skills students should acquire and further develop even after the traditionally determined period of education has been completed. In addition, ESP teachers face a specificity dealing with two subjectmatter fields - the English language and specific subject-matter knowledge, be it science, humanities, engineering, or anything else.

Also, what recently has been shed light on are teaching/learning strategies, different students' abilities and attitudes, and above all, "teachers' understanding of the social, political, cultural and physical environments" (Cochran, 1997) in which students are supposed to learn. Students' background subject-matter knowledge and their previous achievements determine to a great extent what teachers should and have to do in their

Submitted August $27^{\text {th }}, 2018$, accepted for publication October $29^{\text {th }}, 2018$ 
classrooms, how they organize their lectures, type of assignments that students should complete, and other issues germane to their teachability.

Teaching in new contexts and discourses is not only a simple implementation of curricular innovations but, as in dishes thoroughly spiced by a master chef, teachers must always remember - what comes out of their 'cuisine' must be not only 'eatable' but enjoyable and fruitful. It is particularly difficult nowadays when classroom circumstances have changed and new responsibilities are demanded of teachers, while family and social landscape seem to unsuccessfully change their roles. Assessing the situation today and comparing it with the state of affairs at the end of XX century, teachers have to continually acquire more expert knowledge and upgrade their skills, following suit and not falling behind general trends in society. Since ESP has much to do with "a socially situated practice" (McGrath, 2016), this discipline-specific approach incorporates a disciplinary perspective into the course design. ESP practitioners should feel encouraged to step outside their comfort zone and explore new inspiring methods that overcome the existing shortcomings, misconceptions, and traditional boundaries of provisional pedagogical frameworks.

\section{A CREATIVE MANAGER IN THE ClassRoOM}

\subsection{Teacher professional development and managerial skills}

What has been changing over time in teachers' perspective, from pre-service teachers and through the position of novices up to experienced teachers, is surely the way of representing and methodically preparing the subject to make it clear and intelligible to others. It is simply a matter and natural outcome of a long-term practice. It determines both teachers' daily routine in the classroom and their longer-time horizon in future. Learning from students about their thinking offers teachers new ideas related to in-depth explanations, more suitable examples and analogies, and adapting and tailoring the materials according to students' needs.

Coursebooks used in the classroom are usually provided with a step-by-step guide but simply following the instructions in a rather mechanical way can be considerably discouraging and with no challenges. Besides providing rich language input, teachers' ability to improvise is exceptionally valuable. Professional development activities may substantially contribute to boosting such skills in teachers, e.g. watching trendy films and series that capture the attention of students and employing memorable quotes in class, accessing popular profession-based websites on the Internet, using lyrics of popular music, etc. A successful teacher is not only a person with specialist knowledge and prominent personal features but the one with skills and capacities emphasizing particularly his/her managerial qualities. Teachers manage their professional development; they manage classroom activities; they manage existing and future knowledge; they manage their identities within higher education; they manage their own motivation and commitment; they manage educational policy challenges, etc. So, management in education has no end! However, at that very point, we highlight the official criteria of a teacher appointment in Serbia where teacher performance and success in the classroom are much less valued than the number and quality of their published papers and participation in conferences. 


\subsection{Learning is a process, not a goal}

But, in spite of the aforesaid, particular student needs involving "what learners know, don't know or want to know" (Flowerdew, 2013) should be established first. Following this way of approach, teachers enable students to learn by orienting to processes and not just particular goals. For example, language and skills in teaching materials for the students of biology should encompass a variety of topics and situations - the evolution of living beings, fundamentals of animal anatomy, plant morphology, environmental science fieldwork, and communication. After receiving a degree and pursuing further professional development, students may take a 'narrow' ESP course focusing on botany or specific laboratory work and then pay more attention to non-receptive skills - speaking and writing - being of particular importance for occupational purposes. In the meantime, teachers are supposed to be innovative and imaginative enough to alleviate the constraints of such a widely used one-size-fits-all approach in the classroom and compensate for student lacks, satisfy their needs and meet their wants inasmuch as it is possible.

How to conceptualize and organize the instruction content in a domain such as ESP? How to enable that learners develop 'a usable knowledge of English' in their professional fields of education? What is the teacher's role when 'language is supposed to be simultaneously the medium and the object of instruction' (Freeman, 2015) and, in addition, when should specific profession-based topics be discussed in the classroom?

For a start, experienced teachers are well aware that even best-prepared lessons do not always work in the classroom. Of course, it should be taken as a challenge and a chance to further discern and analyse the activity in the classroom. The instructional language needs to be understandable and students should be accustomed to asking for necessary explanations as soon as vagueness appears. In this way, the content supposed to be learnt produces the essence or core motivation in students to live the subject they study, which ultimately makes them - love it.

\subsection{Knowledge transfer and knowledge creation}

Adequate advance planning, encompassing both minute-by-minute classroom activity and overall curriculum design, considerably affect teachers' capacity in getting their job done. When defining their particular tasks, teachers endeavour to make necessary functional categorizations and determine the language skills involved. What we think should be taken care of is to limit the subsets of the language, e.g. syntax or semantics, in favour of the functional terms and vocabulary that are applicable in the particular fields of profession. Since ESP learners appear to be more familiar with their subject-matter topics while their ESP teachers have the role of 'managers' of skills and strategies that ought to be developed in both reception and production of language structures, they all share the responsibility for, call it, knowledge transfer and knowledge creation. With the advent of learner-centred approach to teaching, a number of responsibilities are added to traditional approaches, implying successful dealing with communicative situations and mastering a variety of skills and sub-skills.

Background knowledge in students has a major effect on whatever they are supposed to learn during their university education. Since both general skills and specific knowledge gained earlier affect the retention of newly gained knowledge, more or less effort (and time!) is expected to be invested on both sides - teacher's and students'. Because of varying levels of knowledge, even the best-structured instruction in the 
classroom may be perceived undemanding by high-ability students, and vice versa some students feel anxious while cutting through the 'gobbledygook' to get to the point. The language performance of ESP teachers in both context and task-based instruction is consequently, always expected to be accurate, comprehensive and productive, while students are expected to overcome inner fears and endeavour to improve their own performance to the level deemed necessary not only for passing the exam but for establishing effective on-the-job communication.

\subsection{Illustrative techniques and storytelling makeover}

While talking about methods employed in the classroom, real-life examples are always illustrative and helpful, as might be expected. Teachers are there to draw connections between the real life and familiar issues with the content that is to be apprehended. Information can be recorded using illustrative techniques such as a tree diagram, table, spidergram, flowchart, timeline, etc., in presenting advantages and disadvantages, cause and effect, the sequence of events, stages of processes, etc. Description of items discussed in students' professional domains (e.g. Napier's Bones in IT, frog morphology in biology, crystalline salts in chemistry, etc.), elaboration of working principles and performance (e.g. mechanical versus electronic computers, respiration in living cells, redox potential, etc.), and telling simple stories and anecdotes related to famous scientists scattered throughout lectures help break up the boring sections and encourage students to increase their own contribution to a successful lecture.

Therefore, in our opinion, teachers must be perfect storytellers in the first place since stories are how we remember things and they are perfect tools to attract listeners' attention. Information, emotions, and knowledge are all 'packed' in stories. Inside an ESP classroom, the atmosphere can be made both cosy and fruitful if teachers sometimes resort to a digression telling short stories related to the topic and content discussed there. To mention an example from the classroom, IT students are all familiar with Adobe software packages (Acrobat Reader, Photoshop, Flash, Dreamweaver, etc.), but rarely know anything about the Spanish (Moorish) origin of the word 'adobe' - a mixture of mud and straw used in making bricks in Adobe Creek in California where both founders of the well-known company lived. Science always needs a story. The story always needs a makeover. The makeover must be soundness- and not significance-based.

Concerning narrative, creativity is essential not only in music and art but also in science or IT. Impressive achievements of all times always result from fertile and vivid imagination and teachers ought to be aware of the fact that, regardless of the further professional development of their students, they look at people waiting for a good story and humour as a sophisticated form of intelligence which, surely, improves the retention of knowledge. Of course, students are not only exam takers but imaginative and creative thinkers and for infusing creative thinking the responsibility is on teachers (as envisioned by the Partnership for $21^{\text {st }}$ Century Skills - http://www.p21.org). Thus, teaching and learning become more meaningful and pleasurable.

\subsection{Building communicative competence}

Nevertheless, ESP instructors and practitioners often complain of the paucity of published materials for particular fields of study and work. Numerous textbooks deal with management, business, IT, and technical sectors, but only a small number of titles 
are intended for environmental science, biology and chemistry students, to name but these. The existing scarcity of textbooks does not mean that instructional materials available to teachers for adaption and tailoring are also scarce. For teachers, it seems as a chance for gaining hands-on experience and deepening a discipline-based knowledge. For students - it is a challenge to explore a myriad of sources around.

Even when studying more in depth, be them future communicatively competent managers, analytical chemists or IT professionals, students have a lot to do with building communicative competence via a fundamentally "immersion-like" approach (Belcher, 2004) referred to a particular genre - seminar presentations, lectures, reports and other communicative events. Collecting empirical data and preparing or adapting materials that satisfy the specific student needs are supposed to be ESP teachers' activities providing not only textual but situational context as well. As a result on the students' side, knowledge and competencies gained through ESP courses make their "professional macro-skill" (Whyte, 2017). From that point of view, it would be both useful and interesting to experience twice the same topic-based presentation assigned to a freshman/ sophomore and a senior student at the Department.

In addition to language accuracy, communicative competence and multidisciplinary development in students, practical problem solving is of utmost importance in communication. We remember the situation from a real classroom when the best letter of enquiry was the one with a lot of red-pencil error corrections but with all the necessary sender's details written in the top right corner as well, which is never sufficient for the best mark but is always the most effective problem-solving performance.

\section{GENERAL CONCEPTS AND ORGANISATIONAL FRAMEWORKS}

\subsection{Concept-based teaching and learning}

Surrounded by young learners unwilling to accept taken-for-granted thoughtways, ESP teachers are to pay special attention to concept-based teaching and learning. Before introducing concepts to the class, it is not superfluous to define what a concept is. Somehow, concepts are on some occasions taken as curriculum-mandated topics. However, concepts are broad ideas here - broad enough to be abstract, universal, and everlasting - while topics are subjects, themes or issues that are discussed and dealt with in the classroom. ESP textbooks, most often divided into units including various topics, commonly do not suggest methods of conceptualization. Then, it is up to teachers to adapt and abridge possibly complex and intricate topics through the concepts connecting the subsets of knowledge and skills with students' apprehension. Of course, the choice can be made between specific and universal concepts, former of which is more specificcontent related and latter, surpassing such limited area, covering all subject areas and professional fields. Based on the experience with students of economics, science and IT, we present the following figure with general concepts that may be applied in different domains, even being dealt with in the field of economics, arts or natural sciences.

General concepts exceed the scope of topics - let us look at the example of a forest ecosystem and some of the general concepts that are also applicable in chemistry or medicine. In comparison with the concepts presented in Figure 1, these are less universal and more helpful for students in connecting with the content of a forest ecosystem. Once 
found linkage may help in the explanation of some other systems such as food chain, neural system, herbivore consumption, etc.

\begin{tabular}{|c|c|}
\hline \multicolumn{2}{|l|}{$\theta$} \\
\hline origin & scarcity \\
\hline evolution/development & autonomy \\
\hline diversity & contact \\
\hline CHANGE & performance \\
\hline pattern & productivity \\
\hline community & tree/branch \\
\hline structure & death \\
\hline sustainability & ECONOMY \\
\hline system & relationships \\
\hline
\end{tabular}

Fig. 1 Common general concepts in Economics, Biology, and Language

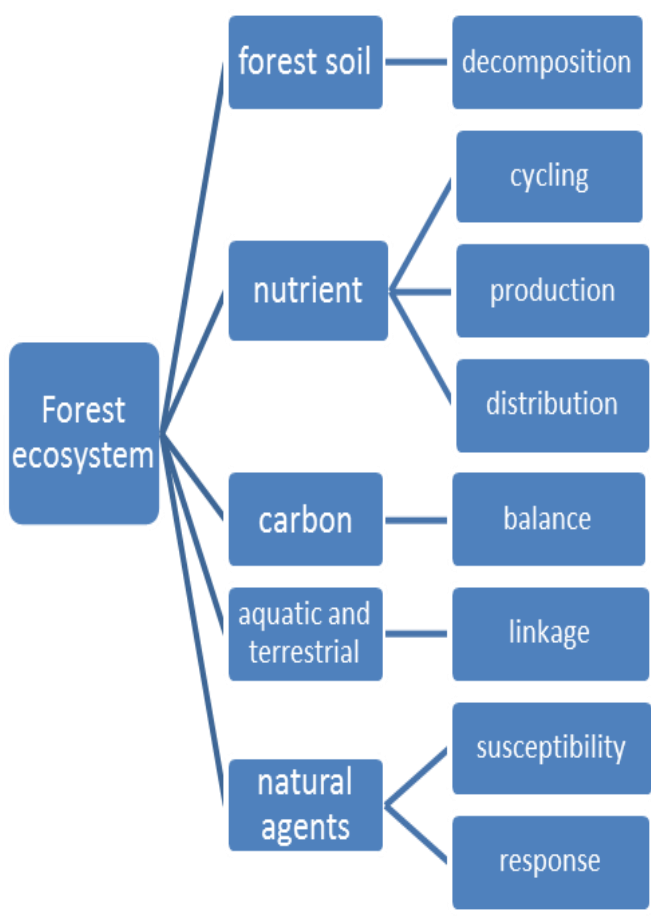

Fig. 2 Forest ecosystem - general concepts

When addressing the problem of semiotic meaning, some authors resort to Conceptual Metaphor Theory (CMT) (Danesi, 2007), finding it a very powerful tool inside the classroom as very efficient in unmasking hidden metaphorical concepts in various kinds of texts. Maybe unjustifiably, the success of this method is attributed to 'a 
pedagogical framework incorporating CMT' although cognitive learning theory, and particularly cognitive grammar, has much more to do with metaphors. Suffice it to say that understanding something unfamiliar and unknown in terms of something familiar and known is closely connected with the methodology of general concepts the implementation of which is elaborated above.

\subsection{A holistic approach and learner-centredness}

Thus, particular aspects of subject matter or subject-specific content are organized and adjusted with a myriad of open-framework 'big ideas' from real life which students are familiar with. And then, there is no special need for a highly scientific engagement of pedagogical principles since pedagogy appears to be nothing more but suitable adaptation of teachers' behaviour, from their posture and facial expression in the classroom to the 'stories they tell', to students' needs in order to accomplish their remarkable achievements deserving respect on both sides.

Namely, teachers have to understand the reasons why learning specific topics is quick and easy or protracted and difficult. Theoretical knowledge of pedagogy may help in some cases, but teachers are, above all, classroom-friendly actors playing lots of characters while using textbooks and realia - visual aids, audio recordings, newspaper articles and video clips - in order to, as a skilful journalist, provide the most thorough answers to basic questions: what/who, where, when, how and why. Since teachers willingly and routinely help students to achieve their goals in learning, their altruistic attitudes and behaviour must not be questionable. Pedagogy does not make a good teacher and we deeply believe that the essence is not in theories and methods employed in the classroom but in the exchange of experiences and a holistic approach to audience to which teachers have to be finely tuned. All the best teachers have not become what they actually are by the book, but owing to perpetual self-scaffolding and self-development as high performers. In this individual activity and finding their own way, teachers set their own goals, make their own decisions, scrutinize their own advancement, and embrace the outcomes of both themselves and their students.

At great length, literature has dealt with learner-centredness - one of the supposed-tobe democratic principles of learning - which enhances student learning and shifts the focus from teachers onto students. Nevertheless, the entire institutional mindset ought to be created in a way that values and supports learner-centredness which means that an organizational reform of the existing educational system (to start with a number of students in a lecture group) is - a must! Only then can 'personalized' teaching and learning be applicable in the classroom. In the meantime, lots of lengthy discussions have been led addressing the distinct learning needs, students' cultural background, and their interests and aspirations, while a way out of the theoretical impasse has not been found. A thorough institutional and organizational reform requires lots of efforts, time and funds and that is why, from an administrative and logistical perspective, the existing teaching and learning are organized in a manageable way: students supervised by teachers, fixed course options, the same textbooks for all, and limited funds for equipment.

Concerning the learner-centredness mentioned above, the impression is that teaching/learning seems to shift the focus onto individualization and self-managed activities which is, under existing conditions, an approach suitable only for smaller numbers of students. Inside an ordinary classroom, if "questioning accounts for up to a 
third of all teaching time" (Husbands, 2012), and most of them are procedural rather than learning based, it appears that higher-order thinking is not attainable by simple "power of talk", but through high-quality teacher-student interaction where "student themselves are drawn into this space as participants in the construction of knowledge" (Lea, 2004) and prepared to be intentional learners.

\subsection{ESP courses for productive knowledge}

Traditional pedagogic creeds have still not be rejected, let alone classroom organization, often ignoring to a great extent a novel multidimensional framework outlined by technological advancement specifically targeted towards activities that developing pragmatic competences. The point of learning is not in memorizing things that are not understood and the application of which has been learnt in practice is, possibly better than in other professional domains, notable in EFL and ESP students. In practice, all Departments of the Faculty of Science (University of Kragujevac) provide lectures in ESP for a larger group and exercises for smaller groups and English teachers/assistants can always count on helping hands of the colleagues (proxy) with expertise in the Faculty majors, thus enabling "pre-teaching" or "re-teaching" as proposed in a particular "co-teaching arrangement" by some authors (Schultze, 2018). In this regard, divergent teaching styles are intertwined to the benefit of both students and all teachers involved in the activity.

In ESP courses special attention is paid to teaching and learning vocabulary of a particular professional domain. Since general truth is that "receptive knowledge (i.e. recognition) is easier to acquire than productive knowledge (i.e. recall)" (Sonbul, 2010), both explicit and incidental learning have to be implemented when teaching/learning vocabulary. Students ought to be introduced to purely technical words with a narrowrange use and without an exact synonym, such as software or isotope, which should be distinguished from words with both technical and non-technical meaning, e.g. channel or pulse. Improvised activities such as brief role-plays based on textbook dialogues may be doubly beneficial here: they enhance the comprehension and memorizing of new vocabulary and elicit a positive response encouraging students to freely produce their own utterances in a foreign language. It is important for students to recall both form and meaning of the adopted vocabulary over time, even though they are probably unaware of the exact connotations in the classroom, for which multiple-choice test can be very helpful in meaning recognition. Language is always words and thus mastering both English language subject-matter-knowledge (the entire correctness of word combinations) and English language proficiency (expressing the knowledge acquired) do boost students' self-estimation and self-confidence. What also should be emphasized here is that a pencil and paper exceed the value of the computer in this case since the ownhand written words are kept in memory longer in comparison with the words seen in a presentation on the computer.

Of course, different disciplines have diverse organizational frameworks and practices, although some universal methods of presentation may be employed in all domains ESP teachers deal with, such as visual aids, video clips, and computer simulations that enhance comprehension and entice students to actively take part. First-hand experience is always precious but is gained differently, e.g. software programming is based on different learning postulations in comparison with growing a plant, although in both cases teachers 
are required to understand and (successfully) apply 'cognitive, social, and developmental theories of learning' (Harris, 2009). Sometimes, ESP teachers may even be in danger of becoming outdated because of accelerated advancement in particular professional domains of their students' (e.g. ICT).

\subsection{New technologies and disciplinary contents}

Computer simulations, as mentioned above, may greatly contribute to understanding different phenomena, and disciplinary content, in general, may fundamentally be changed due to the new technology employed in teaching and learning. Electricity, penicillin, nuclear fission, and the Internet, are certainly among the most impactful technology inventions of all times - the last profoundly shaping the history of ours. New technologies and disciplinary contents are here in a specific relationship - the former inspiring the ways of thinking in both teachers and students and the latter leading, and sometimes even dictating, the forms of technologies employed in the field of education. Talking about technology, we should bear in mind that no single technological solution is suitable for every classroom and the people inside. A possible approach based on the combination of various wellsprings of knowledge may be presented as follows in Table 1 .

Table 1 Wellsprings of knowledge - sources and technologies

\begin{tabular}{|l|l|}
\hline Source/Activity & Technologies \\
\hline Visual aids & drawing; animation; video; concept mapping \\
Text reading & e-books; CDs; the Internet \\
Discussion & forums; chatrooms; e-mail \\
Virtual trip & online laboratories; virtual reality \\
Research & web browsers; online libraries \\
Presentation & whiteboards; video projection screen \\
Listening & CDs; podcasts; radio; MP3 \\
First-hand practice & interactive software; database search \\
Artefact analysis & prototypes; models; video games \\
Assessment & quiz software; online test \\
& \\
\hline
\end{tabular}

Student knowledge expression may come in divergent activity types - visual, written, artefact production or a debate. The point here is not in assessing what they have prepared, but in encouraging a brainstorming session. For example, after keeping diary notes inside a chemistry lab, students may review chemical reaction pathways; using illustrations (cartoons, pie-charts, etc.) they can discuss a particular issue as presented; skimming a text after reading, students can prepare an abstract, or, they can prepare questions for an imagined interview with a Nobel-prize winner in the field of their interest; IT students can develop graphics software and biology students can produce a model of skin aging; based on video material, students can prepare role-plays or debates. The employment of particular activity types depends on affordances and constraints imposed by field-specific characteristics and discipline-based instruction. 
It should not be neglected that "deriving a conceptualization deductively from literature and validating and fine-tuning it by empirical-inductive methods" (Hubwieser, 2013) shed light on the knowledge, skills, and competencies of teachers as the most significant factors determining the learning success of their students. We intentionally emphasise teachers' subject-matter knowledge first, since in our opinion, as has been said earlier, pedagogical knowledge appears to be unjustifiably favoured over domain-based knowledge especially when problem solving and a growth mindset are considered the $21^{\text {st }}$ century competencies.

\subsection{Dominant paradigms of ICT vs 'disruptive pedagogy'}

Talking about enhancing competencies, the British Council, for the fifth year in a row, organized the conference and fair 'New Technologies in Education 2018' in Belgrade (https://www.britishcouncil.rs/en/new-technologies), pointing out the use of educational technologies which some practitioners have been criticizing since it is "driven more by the imperatives of technology than by sound pedagogical reasons" (Mishra, 2006). However, we cannot think back to the example in this field where novelty loses ground to tradition. Encouraging creativity and the development of core skills and algorithmic thinking has become a cornerstone of modern education in which ICT makes dominant paradigms and traditional pedagogy is to leave a prominent place. Instead of 'serving lunch', teachers today are mostly top-notch chefs offering 'cookbooks' and putting aside a so-called 'disruptive pedagogy'.

Has the reality in education really "lagged far behind the vision" (Mishra, 2006)? Are general pedagogical practices overemphasized and often at the expense of content knowledge? In our opinion, teachers' knowledge of student thinking and learning is more related to their emotional intelligence and psychology than pedagogy. Instead of memorizing facts, students are to be taught to search for information, to connect things, and enable the development of integrative knowledge in a multidisciplinary education. In such a learning environment, the responsibility of teachers is not only in their teaching but in facilitating learning by doing. Creative strategies to inspire learning are always welcome in all classrooms: Agatha Christie's mysteries and evidence-based storytelling was a successful example in teaching/learning about (forensic) chemistry in our classroom.

\section{CONCLUSION}

Students are different. Teachers are also different. Since various factors affect the processes of teaching and learning, such as age (of both students and teachers), cultural environment, previous experiences and knowledge, cognitive abilities, willingness to teach/learn, etc., they both must be aware of the 'Open Sesame' word. It is patience. Teachers who are persistent, patient and dependable and students who never give up are right on track to distinguish themselves. In doing so, both "declarative knowledge (knowledge about something) and procedural knowledge (the ability to do things)" (Richards, 2017) are of utmost importance for each party in the process. Teachers' ability to use English in a way that encourages learning in their students, where accuracy, fluency, and intelligibility are implied as necessary, is in our opinion, above all theories, especially in times when motivation in students is constantly decreasing and dazzling lights 'are killing softly' our society of gadgets and gizmos. 


\section{REFERENCES}

Belcher, Diane. "Trends in Teaching English for Specific Purposes." Annual Review of Applied Linguistics 24 (2004): 165-186.

Cochran, Kathryn F. 'Pedagogical Content Knowledge: Teachers' Integration of Subject Matter, Pedagogy, Students, and Learning Environments." Research Matters - to the Science Teacher 9702 (January 1997). https://www.narst.org/publications/research/pck.cfm (10 June 2018)

Danesi, Marcel. "A conceptual metaphor framework for the teaching of mathematics." Studies in Philosophy and Education 26 (May 2007): 225-236.

Flowerdew, Lynne. "Needs Analysis and Curriculum Development in ESP" in The Handbook of English for Specific Purposes. (2013): 325-346

Freeman, D., Anne Katz, Pablo Garcia Gomez, and Anne Burns. ''English-for-Teaching: rethinking teacher proficiency in the classroom." ELT Journal 69:2 (April 2015): 129-139.

Harris, J., Mishra, P., and Matthew Koehler. 'Teachers' Technological Pedagogical Content Knowledge and Learning Activity Types: Curriculum-based Technology Integration Reframed.' Journal of Research on Technology in Education 41:4 (2009): 393-416.

Hubwieser, P., Andreas Muhling, Johannes Magenheim, and Alexander Ruf. '’Towards a Conceptualization of Pedagogical Content Knowledge for Computer Science." Proceedings of the ninth annual international ACM conference on International computing education research. ICER '13. ACM. New York, NY, USA, (2013):1-8. http://doi.acm.org/10.1145/2493394.2493395 (20 May 2018).

Husbands, C., and Jo Pearce. 'What makes great pedagogy? Nine claims from research." Research and development network national themes: theme one (2012): 1-16.

Lea, Mary R. "Academic literacies: a pedagogy for course design." Studies in Higher Education 29:6 (December 2004): 739-756.

McGrath, L., and Kathrin Kaufhold. 'English for Specific Purposes and Academic Literacies: eclecticism in academic writing pedagogy." Teaching in Higher Education 21:8 (2016): 933-947.

Mishra, P., and Matthew J. Koehler. '’Technological Pedagogical Content Knowledge: A Framework for Teacher Knowledge.' Teachers College Record 108:6 (June 2006): 1017-1054.

Richards, Jack C. ''Teaching English through English: Proficiency, Pedagogy and Performance."' RELC Journal 48:1 (2017): 7-30.

Schultze, F., and Pernilla Nilsson. 'Coteaching with senior students - a way to refine teachers' PCK for teaching chemical bonding in upper secondary school.' International Journal of Science and Education 40:6 (2018): 688-706.

Sonbul, S., and Norbert Schmitt. 'Direct teaching of vocabulary after reading: is it worth the effort?.' ELT Journal 64:3 (July 2010): 253-260.

Whyte, S., and Cedric Sarre. 'Introduction to new developments in ESP teaching and learning research.' In C. Sarre \& S. White (Eds) New developments in ESP teaching and learning research (2017): 1-12.

http://www.p21.org (accessed in June 2018)

https://www.britishcouncil.rs/en/new-technologies (accessed in July 2018) 